\title{
Dielectric Relaxation of Polar Molecules in Benzene Medium at Microwave
}

\author{
S. B. Gedam and B. M. Suryavanshi
}

\begin{abstract}
The dielectric constant $\left(\varepsilon^{\prime}\right)$ and $\operatorname{loss}\left(\varepsilon^{\prime \prime}\right)$ of polar liquids in solutions of benzene have been determined at room temperature $(270 \mathrm{C})$ at fixed microwave frequency $(10.15 \mathrm{GHz})$. It is observed that dielectric constant and loss varies with concentration linearly. The studies report a determination of relaxation time $(\tau)$ electric dipole moment $(\mu)$ of Polar liquids in benzene solution at room temperature.
\end{abstract}

Index Terms-Dielectric constant, dilute solution, relaxation time, dipole moment.

\section{INTRODUCTION}

Studies of dielectric constant, of polar liquids, especially in dilute solutions in non-polar medium have a important role in liquid state [1]-[5]. Dielectric constant is aelectrical property of substances, which is due to contribution from orientation, vibration and electronic polarization in polar liquid. Dielectric investigations mainly probe weak forces between the molecules and help to understand intermolecular reorientational dynamics of the solute as well. In the present paper, we have carried out dielectric measurements of a polar liquid in a non-polar medium (benzene) at $27^{\circ} \mathrm{Cat}$ single microwave frequency $(10.15 \mathrm{GHz}$.). The results are discussed to interpret molecular structure $\mathrm{n}$ terms of relaxation time $(\tau)$ and electric dipole moment $(\mu)$ of the dipole in the medium.

\section{EXPERIMENTAL}

All polar liquids (Merck Specialties) and non-polar Benzene (sd-fine chem.) of AR grade obtained commercially and were used without any further purification. Dilute solutions of polar liquid for few dilute concentrations in Benzene. The solution were mixed well and kept for $12 \mathrm{Hrs}$. in a well stopper volumetric flask to ensure good thermal equilibrium. These systems in non-polar benzene were assumed to be dilute solutions.

The X-band microwave bench was used to measure the wavelength of the microwave radiation in liquid dielectric cell. The liquid sample was hold vertically in a liquid cell by supporting a thin mica sheet whose VSWR and attenuation were assumed negligible small. The liquid dielectric cell was attached at the end of microwave bench. The Smyth's equations [6], [7] are used to calculate dielectric constant, dielectric losses at microwave frequency.

Manuscript received March 10, 2013; revised May 16, 2013.

S. B. Gedam is with the Department of Physics, M. G. College Armori Dist., Gadchiroli, India 441208 (e-mail: dr.shashigedam@rediffmail.com).

B. M. Suryavanshi is with the Department of Physics, Govt. Institute of Science, Nagpur-440001, India.

$$
\begin{gathered}
\varepsilon^{\prime}=\left\{\lambda_{0} / \lambda_{c}\right\}^{2}+\left\{\lambda_{0} / \lambda_{d}\right\}^{2} \\
\varepsilon^{\prime \prime}=2 / \pi\left[\lambda_{0} / \lambda_{d}\right]^{2}\left[\lambda_{g} / \lambda_{d}\right]^{2}
\end{gathered}
$$

where,

$\lambda_{0}$ - Wavelength of mirowave radiation.

$\lambda_{0}$ - Cutoff wavelength in the wave guide.

$\lambda_{d^{-}}$Wavelength of mirowave radiation in liquid medium.

The procedure of measurement on X-band is describe elsewhere [4]-[6].

A Gopala Krishna method [8] based on Debye molecular model, (3) is used to determine a relaxation time $(\tau)(4)$ and electric dipole moment $(\mu)$ from (5).

$$
\left[\varepsilon^{*}-1 / \varepsilon^{*}-2\right]=\left[\varepsilon_{\infty}-1\right] /\left[\varepsilon_{\infty}-2\right]+\left[4 \pi \eta \mu^{2} / 9 K T\right][1 /(1+j \omega \tau)
$$

where,

$$
\begin{gathered}
\varepsilon^{*=}{ }_{\varepsilon-j} \varepsilon^{\prime} \\
\tau=(1 / \omega)(d y / d x) \\
\mu^{2}=9 K T M / 4 \pi N d_{0}\left\{1+(d y / d x)^{2}\right\} d x / d w
\end{gathered}
$$

where, the meaning of symbols are standered and variation of $\mathrm{x}$ and $\mathrm{y}$ are depend on concentrations of the polar liquid in non-polar medium.

\section{RESUlT AND DISCUSSION}

The physical and Molecular constants of polar and non polar compounds are mentioned in Table I, below

TABLE I: THE PHYSICAL AND MOLECULAR CONSTANTS OF POLAR

\begin{tabular}{|l|l|l|l|l|l|}
\hline Comp. & Mol.wt & $\begin{array}{l}\text { M.P. } \\
{ }^{\circ} \mathrm{c}\end{array}$ & $\begin{array}{l}\text { B.P. } \\
{ }^{\circ} \mathrm{c}\end{array}$ & R.I. & $\begin{array}{l}\text { Density } \\
\text { Gm/cc }\end{array}$ \\
\hline Benzene & 78.11 & 05 & 80 & 1.5010 & 0.874 \\
\hline Acetone & 58.08 & -94 & 56 & 1.3585 & 0.791 \\
\hline Pyridine & 79.10 & -42 & 115 & 1.5102 & 0.978 \\
\hline Nitrobenzene & 123.11 & 5.6 & 210 & 1.5513 & 1.196 \\
& & & & & \\
\hline
\end{tabular}

The determined values of dielectric constant $\left(\varepsilon^{\prime}\right)$ and dielectric losses $\left(\varepsilon^{\prime \prime}\right)$ of Acetone in benzene solution are reported in Table II.

To determine relaxation time $(\tau) \mathrm{Y}$ and $\mathrm{X}$ are plotted, which is linear Fig. 1.

$\mathrm{X}$ and $\mathrm{W}$ are plotted which is also linear Fig. 2 determines Dipole moment $(\mu)$ of polar liquids in non- polar benzen medium . 
The determined values of dielectric constant $\left(\varepsilon^{\prime}\right)$ and dielectric losses $\left(\varepsilon^{\prime \prime}\right)$ of Pyridine in benzene solution are reported in Table III.

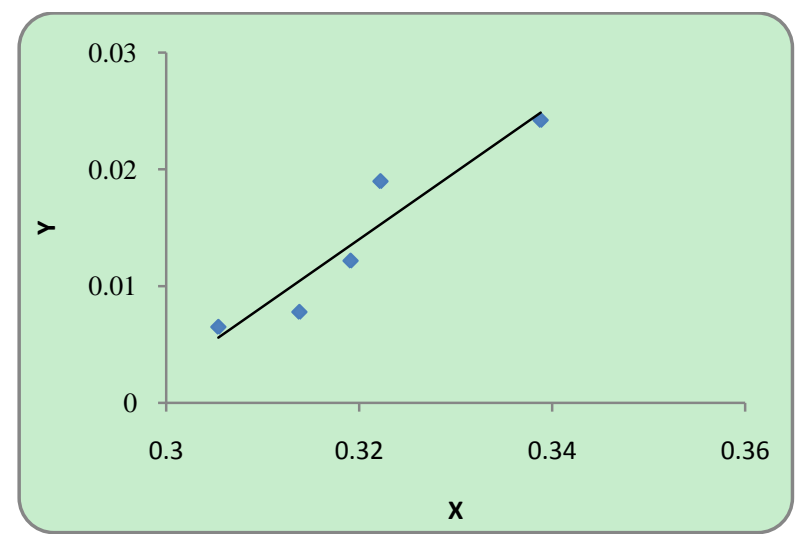

Fig. 1. Linear behavior of acetone between $\mathrm{Y}$ and $\mathrm{X}$.

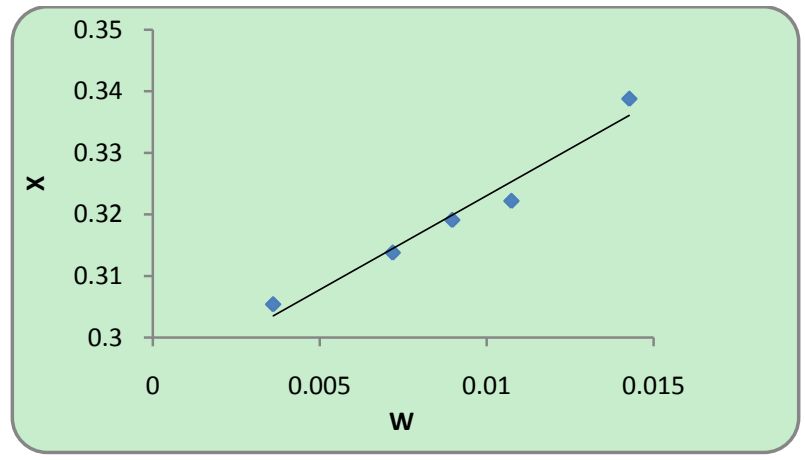

Fig. 2. Linear behavior of $\mathrm{X}$ and $\mathrm{W}$ for acetone in benzene.

TABLE II: The Determined VAlues of Dielectric Constant $\left(\varepsilon^{\prime}\right)$ AND DIELECTRIC LOSSES $(\varepsilon ')$ OF ACETONE IN BENZENE SOLUTION

\begin{tabular}{|c|c|c|c|c|c|}
\hline $\mathbf{S}$ & $\begin{array}{c}\text { Wt. } \\
\text { fraction } \\
\mathbf{( W )}\end{array}$ & $\boldsymbol{\varepsilon}$ & $\boldsymbol{\varepsilon}$, & $\mathbf{X}$ & $\mathbf{Y}$ \\
\hline 1 & 0.003607 & 2.3188 & 0.04043 & 0.3054 & 0.006502 \\
\hline 2 & 0.007188 & 2.3719 & 0.04960 & 0.3138 & 0.007784 \\
\hline 3 & 0.008969 & 2.4045 & 0.07871 & 0.3191 & 0.012168 \\
\hline 4 & 0.01074 & 2.4225 & 0.1238 & 0.3222 & 0.01897 \\
\hline 5 & 0.01427 & 2.5309 & 0.1658 & 0.3388 & 0.02420 \\
\hline
\end{tabular}

TABLE III: THe Determined VAlues of Dielectric Constant ( $\left.\varepsilon^{\prime}\right)$ AND DiELECTRIC LOSSES $(\varepsilon ')$ OF Pyridine IN BENZENE SOLUTION

\begin{tabular}{|c|c|c|c|c|c|}
\hline $\begin{array}{c}\text { S } \\
\mathbf{N}\end{array}$ & $\begin{array}{c}\text { Wt. } \\
\text { fraction } \\
(\mathbf{W})\end{array}$ & $\boldsymbol{\varepsilon}$ & $\boldsymbol{\varepsilon} \boldsymbol{y}^{\prime}$ & $\mathbf{X}$ & $\mathbf{Y}$ \\
\hline 1 & 0.01107 & 2.3064 & 0.0531 & 0.3035 & 0.008589 \\
\hline 2 & 0.01325 & 2.3747 & 0.0627 & 0.3144 & 0.009826 \\
\hline 3 & 0.01542 & 2.4140 & 0.1073 & 0.3207 & 0.01651 \\
\hline 4 & 0.01759 & 2.4314 & 0.1243 & 0.3235 & 0.01897 \\
\hline 5 & 0.01974 & $2 . .4712$ & 0.2032 & 0.3304 & 0.03043 \\
\hline
\end{tabular}

To determine relaxation time $(\tau)$ and dipole moment $(\mu) \mathrm{X}$ and $\mathrm{Y}$ are plotted, which linear Fig. 3.

$\mathrm{X}$ and $\mathrm{W}$ are plotted which is also linear fig (4) determines Dipole moment $(\mu)$ of polar liquids in non- polar benzen medium.

A plot of $\mathrm{Y}$ versus $\mathrm{X}$ is linear and which determines the value of relaxation time and a plot of $\mathrm{X}$ versus $\mathrm{W}$ (weight fraction) determine the value of electric dipole moment of Pyridine.

The determined values of dielectric constant $\left(\varepsilon^{\prime}\right)$ and dielectric losses $(\varepsilon$ "') of Nitrobenzene in benzene solution are reported in Table IV.

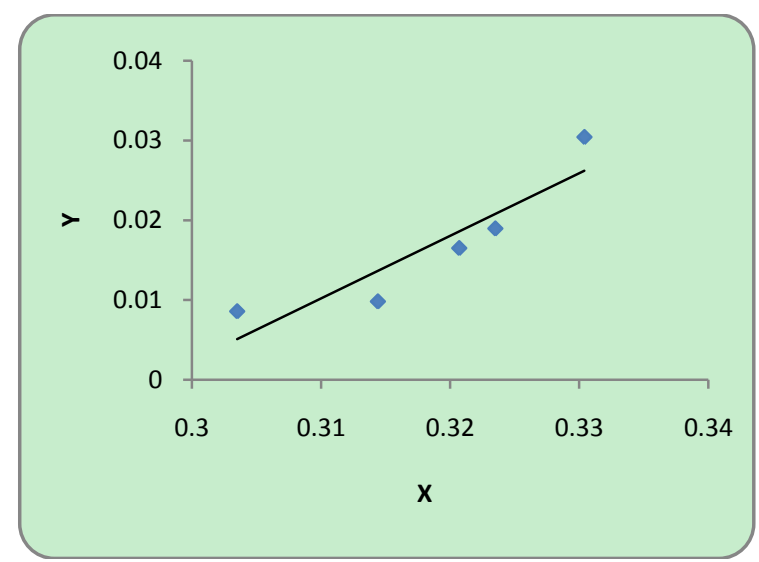

Fig. 3. Linear behavior relation of $\mathrm{Y}$ and $\mathrm{X}$ for Pyridine in benzene

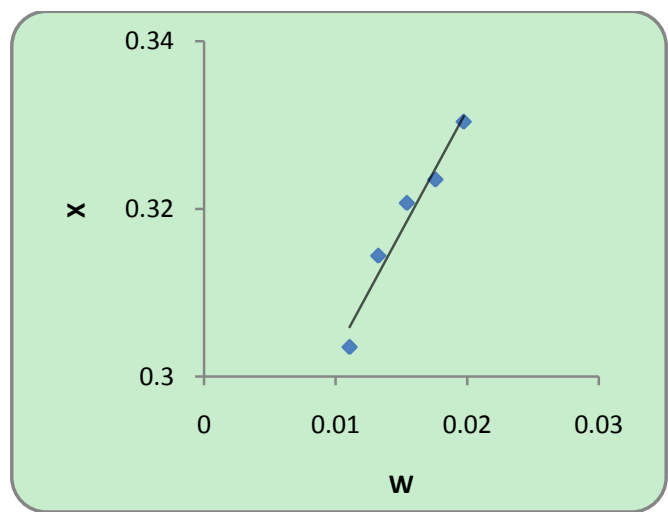

Fig. 4. Linear behavior of $\mathrm{X}$ and $\mathrm{W}$ for pyridine in benzene.

TABLE IV: The Determined VALues of Dielectric Constant $\left(\varepsilon^{\prime}\right)$ AND DIELECTRIC LOSSES $(\varepsilon ')$ OF NITROBENZENE IN BENZENE SOLUTION

\begin{tabular}{|c|c|c|c|c|c|}
\hline $\mathbf{S}$ & $\begin{array}{c}\text { Wt. } \\
\text { fraction } \\
\mathbf{( W )}\end{array}$ & $\boldsymbol{\varepsilon}$ & $\boldsymbol{\varepsilon}{ }^{\prime}$ & $\mathbf{X}$ & $\mathbf{Y}$ \\
\hline 1 & 0.002729 & 2.3196 & 0.07866 & 0.3057 & 0.01264 \\
\hline 2 & 0.005443 & 2.4083 & 0.1901 & 0.3207 & 0.02929 \\
\hline 3 & 0.008143 & 2.4159 & 0.3220 & 0.3242 & 0.04928 \\
\hline 4 & 0.010528 & 2.4782 & 0.3473 & 0.3341 & 0.05164 \\
\hline 5 & 0.013499 & 2.5476 & 0.5648 & 0.3503 & 0.08069 \\
\hline
\end{tabular}

To determine relaxation time $(\tau) \mathrm{Y}$ and $\mathrm{X}$ are plotted, which is linear Fig. 5.

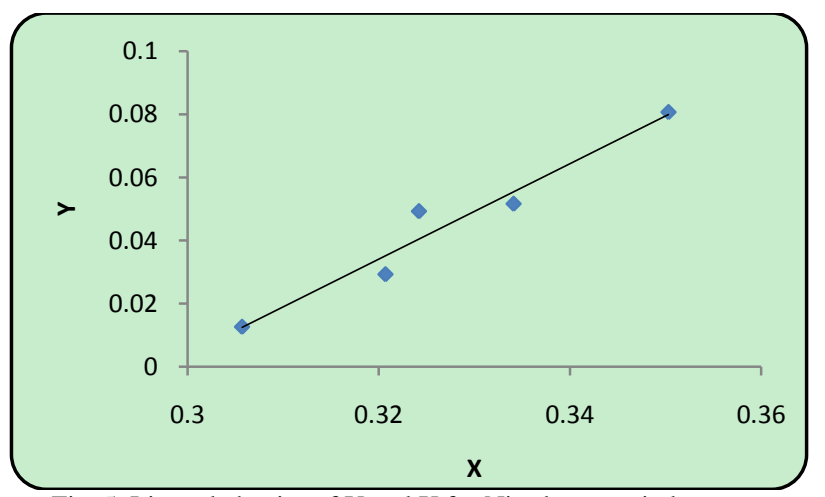

Fig. 5. Linear behavior of $\mathrm{Y}$ and $\mathrm{X}$ for Nitrobenzene in benzene. 
$\mathrm{X}$ and $\mathrm{W}$ are plotted which is also linear Fig. 6 determines Dipole moment $(\mu)$ of Nitrobenzene in non- polar benzene medium.

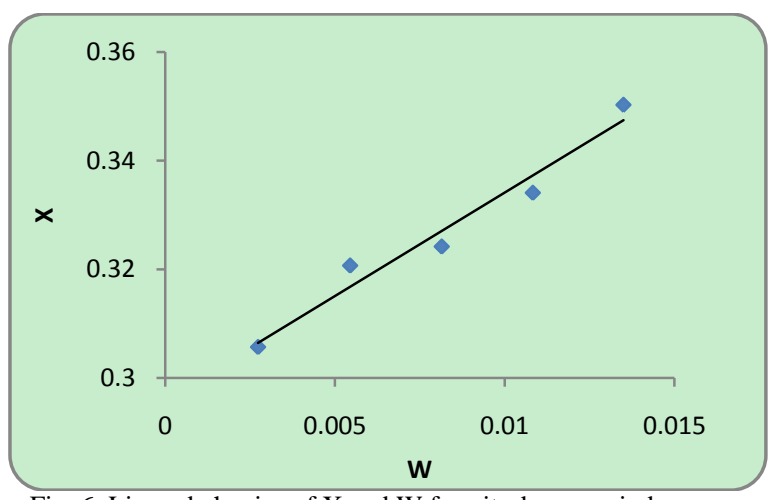

Fig. 6. Linear behavior of $\mathrm{X}$ and $\mathrm{W}$ for nitrobenzene in benzene.

Determines Dipole moment $(\mu)$ and relaxation time $(\tau)$ of polar liquids in non- polar benzen medium is given in Table V. below.

TABLE V: DETERMines DiPole MOMENT $(\mu)$ AND RELAXATION Time $(\tau)$ OF POLAR LIQUIDS IN NON-POLAR BENZEN MEDIUM

\begin{tabular}{|l|l|l|l|l|l|}
\hline Polar Liquids & $\begin{array}{l}\text { Mol. } \\
\text { Wt. }\end{array}$ & \multicolumn{2}{l|}{$\begin{array}{l}\text { Relaxation } \\
\text { Time in ps }\end{array}$} & \multicolumn{2}{l|}{$\begin{array}{l}\text { Dipole moment } \\
\text { in D }\end{array}$} \\
\cline { 3 - 6 } & & Exp & Lit. & Expt & Lit \\
\hline Acetone & 58.0 & 2.3940 & 2.15 & 2.4801 & 2.67 \\
\hline Pyridine & 79.10 & 3.319 & 4.35 & 2.2799 & 2.25 \\
\hline Nitrobenzene & 123.11 & 10.738 & 11.0 & 4.3208 & 3.96 \\
\hline
\end{tabular}

\section{CONCLUSIONS}

The values of dielectric constant $\left(\varepsilon^{\prime}\right)$, and dielectric loss $(\varepsilon ')$ of polar liquids in dilute solution of benzene increase as function of concentration of polar substance. The concentrations of the solution were sufficiently dilute to minimize the solute-solute interaction. The value of relaxation time and electric dipole moment of polar molecules in non-polar benzene are obtained and compared with literature value [9]-[12].

\section{ACKNOWLEDGMENT}

F. A. Author thank to Dr. L. H. Khalsa, Pricipal, M. G. College Armori for encouragement and UGC WR Pune for grant of Teacher fellowship under faculty improvement program \{F.No.32-09(WRO)\}.S. A. Auther thanks to UGC WR Pune for grant of Minor research Project (No. F.4)-10/2003 to develop X-band bench in the department.

\section{REFERENCES}

[1] N. E. Hill, W. E. Voughan, A. P. Price, and M. Davies, "Dialectic properties and molecular behavior," VanNorstand, Reinhold, London, 1969,232

[2] A. Chelkows, Dielectric physics, New York: Elsevies Scientific Publishing Co., 1980.

[3] A. Dhar and P. S. Sastry, Ind. J.P. App. Phy., vol. 27, pp. 178, 1989.

[4] R. Pande, P. G. Gawali, B. S. Narwade, G. Rabbani, and G. M Kalmase, Microwaves and optoelectronics, M. D. Shirsat (Ed.), Anamaya Publishing, vol. 90, Delhi, 2004.

[5] R. Pande, P. G. Gawali, B. S. Narwade, G. Rabbani, and G. M. Kalmase, Microwaves and optoelectronics, M. D. Shirsat (Ed.), Anamaya Publishing, vol. 94, Delhi, 2004

[6] M. L. Sisodia and G. S. Raghuvanshi, Basic microwave techniques and laboratory manual, New Delhi: WielyEstern Ltd., 1990.

[7] W. M. Heston, A. D. Franklin, E. J. Hennell, and C. P. Smyth, J. Am. Chem. Soci., vol. 72, pp. 3443, 1950.

[8] K. V. Gopala Krishna, Trans Farad, vol. 53, pp. 767, 1957.

[9] M. Ghosh, K. Sengupta, and S. K. Roy, Ind. J. Pure. App. Phy., vol. 17, no. 1 , pp. 750, 1973.

[10] V. S. Rangra and D. R. Sharam, I. J. P. Appl. Phys., vol. 41, pp. 630, 2003.

[11] B. M. Suryavanshi and S. C. Mehrotra, Ind J. Pure Appl. Phys., vol. 29, pp. 482, 1991.

[12] B. M. Suryavanshi, "Study of rotational dielectric relaxation by non-resonance spectroscopy at microwave," Frequency, Aug. 1987.

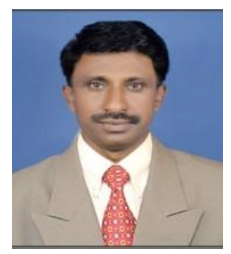

S. B. Gedam was born on 16th March, 1970, at Armori ta, Armori Dist, Gadchiroli, Maharashtra state, India. He is an assistant professor in Dept. of Physics, M. G. College Armori. Dist., Gadchiroli (India) and has 15 years experience. He got fellowship by University Grand Commission, New Delhi for Ph.D. His research interest is in Field of Dielectrics.

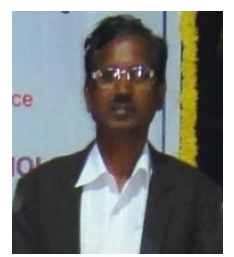

B. M. Suryavanshi was born on 7 August, 1956, at Togri Ta, Latur District, Maharashtra state, India. He is an associate professor and head of Dept. of Physics, in Govt Institute of Science Nagpur (M.S.) India, and has 25 years experience. He is also Research Supervisor of R.T.M. Nagpur University, Nagpur (M.S.) India. Six students completed Ph.D. under his supervision. His research fields are dielectrics relaxations, ultrasonic and inorganic and organic thin films, solar cells. 